\title{
Tumor-targeting Salmonella typhimurium A1-R prevents experimental human breast cancer bone metastasis in nude mice
}

\author{
Shinji Miwa ${ }^{1,2,3}$, Shuya Yano ${ }^{1,2}$, Yong Zhang ${ }^{1,2}$, Yasunori Matsumoto², Fuminari \\ Uehara $^{1,2}$, Mako Yamamoto ${ }^{1,2}$, Yukihiko Hiroshima ${ }^{1,2}$, Hiroaki Kimura ${ }^{3}$, Katsuhiro \\ Hayashi $^{3}$, Norio Yamamoto ${ }^{3}$, Michael Bouvet ${ }^{2}$, Hiroyuki Tsuchiya ${ }^{3}$, Robert M. \\ Hoffman $^{1,2}$ and Ming Zhao ${ }^{1}$ \\ ${ }^{1}$ AntiCancer, Inc.; San Diego, California USA \\ 2 Department of Surgery; University of California, San Diego; San Diego, California USA \\ ${ }^{3}$ Department of Orthopedic Surgery; Kanazawa University Graduate School of Medical Sciences; Kanazawa, Ishikawa, Japan \\ Correspondence to: Robert M. Hoffman, email: all@anticancer.com \\ Keywords: breast cancer, bone metastasis, GFP, RFP, bacterial therapy, Salmonella typhimurium A 1-R \\ Received: July 1, 2014 \\ Accepted: July 16, 2014 \\ Published: July 16, 2014
}

This is an open-access article distributed under the terms of the Creative Commons Attribution License, which permits unrestricted use, distribution, and reproduction in any medium, provided the original author and source are credited.

\section{ABSTRACT}

Bone metastasis is a lethal and morbid late stage of breast cancer that is currently treatment resistant. More effective mouse models and treatment are necessary. High bone-metastatic variants of human breast cancer cells were selected in nude mice by cardiac injection. After cardiac injection of a high bone-metastatic variant of breast cancer, all untreated mice had bone metastases compared to only $20 \%$ with parental cells. Treatment with tumor-targeting Salmonella typhimurium A1-R completely prevented the appearance of bone metastasis of the high metastatic variant in nude mice $(P<0.001)$. After injection of the highly bone-metastatic breast cancer variant to the tibia of nude mice, $S$. typhimurium A1-R treatment significantly reduced tumor growth in the bone $(P<0.001)$. These data indicated that $S$. typhimurium A1-R is useful to prevent and inhibit breast cancer bone metastasis and should be of future clinical use for breast cancer in the adjuvant setting.

\section{INTRODUCTION}

Bone metastasis is found in more than $80 \%$ of patients in advanced stages of breast cancer [1] and is highly treatment resistant and results in extreme pain and high mortality. More effective mouse models and treatment are necessary.

S. typhimurium, which is a facultative anaerobe, was previously attenuated with purine and other auxotrophic mutations, for cancer therapy [2]. In a Phase I clinical trial on patients with metastatic melanoma and renal cell carcinoma, the S. typhimurium strain tested (VNP20009) was attenuated by lipid A-modified $(m s b B)$ and purine auxotrophic (purl) mutations. VNP20009 was safely administered to patients but colonized the patients' tumors to a limited extent, perhaps because it was over-attenuated [3].

Another strain of S. typhimurium, A1-R, has been developed by our laboratory which has increased antitumor efficacy. S. typhimurium A1-R is auxotrophic for Leu-Arg which prevents it from mounting a continuous infection in normal tissues, but does not inhibit tumor targeting and virulence. S. typhimurium A1-R has no other attenuating mutations as does VNP20009 and, therefore, may have higher tumor virulence.

The ability to grow in viable tumor tissue may account, in part, for the unique antitumor efficacy of $S$. typhimurium strains [4]

S. typhimurium A1-R was able to eradicate primary and metastatic tumors in monotherapy in nude mouse models of prostate, breast, and pancreatic cancer, as well as sarcoma and glioma [4-10]. Tumors with a high degree of vascularity were more sensitive to $S$. typhimurium A1$\mathrm{R}$, and vascular destruction appears to play a role in $S$. typhimurium A1-R antitumor efficacy [11,12]. Tumor vessel destruction and tumor-growth inhibition was 
enhanced by primer dosing of $S$. typhimurium A1-R in immunocompetent transgenic mice expressing the nestindriven green fluorescent protein (ND-GFP), which is selectively expressed in nascent blood vessels [13].

S. typhimurium A1-R targeted the Lewis lung carcinoma (LLC) growing subcutaneously in nude mice [14] whereby the bacterially-infected cancer cells greatly expanded and burst and lost viability [15].

We have also shown that S. typhimurium A1-R can target chemo-resistant pancreatic cancer stem-like cells [16] and pancreatic cancer patient-derived orthotopic xenograft (PDOX) models [17-19].

In the present study, we demonstrate that $S$.

a

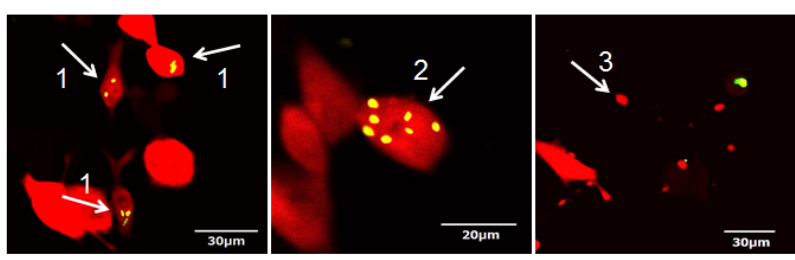

b

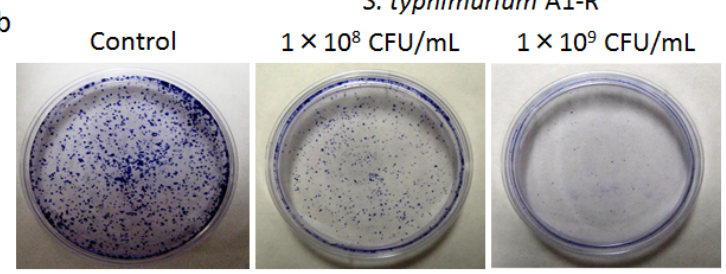

C

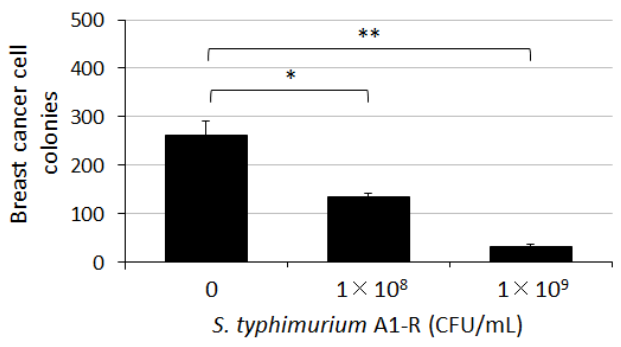

Figure 1: Efficacy of $S$. typhimurium A1-R in vitro on breast cancer cells. Clonogenic assays were performed as previously described [26]. MDA-MB-435-RFP or MDA-MB435-GFP cells were planted in $35 \mathrm{~mm}$ dishes. MDA-MB-435RFP cells were observed $24 \mathrm{~h}$ after the $S$. typhimurium A1-R treatment with the FV1000 confocal microscope. MDA-MB435-GFP colonies were fixed with methanol and stained with $1 \%$ crystal violet 8 days after $S$. typhimurium A1-R treatment. ImageJ (National Institutes of Health, Bethesda, Maryland, USA) was used to quantify the colonies of the cells. a) $S$. typhimurium A1-R expressing GFP invaded (arrow 1) and replicated intracellularly (arrow 2) in MDA-MB-435-RFP cells. The infected cells fragmented (arrow 3). b) S. typhimurium A1-R inhibited proliferation of MDA-MB-435-GFP cells in a dose-dependent manner. c) MDA-MB-435-GFP colony number after A1-R treatment. ${ }^{*} p<0.05, * * p<0.01$ compared with the control group. typhimurium A1-R can prevent human breast cancer bone metastasis using a metastatic variant in nude mouse models.

\section{RESULTS AND DISCUSSION}

\section{Efficacy of S. typhimurium A1-R on MDA-MB-435 cells in vitro}

To determine the efficacy on breast cancer cells, MDA-MB-435 cells, were treated with $S$. typhimurium A1-R for $1 \mathrm{~h}$. Fluorescence imaging demonstrated that $S$. typhimurium A1-R expressing GFP selectively invaded and replicated intracellularly in the MDA-MB-435 cells expressing RFP (Fig. 1a). Clonogenic assays demonstrated that $S$. typhimurium A1-R inhibited proliferation of MDAMB-435-GFP cells in a dose-dependent manner (Fig. 1).

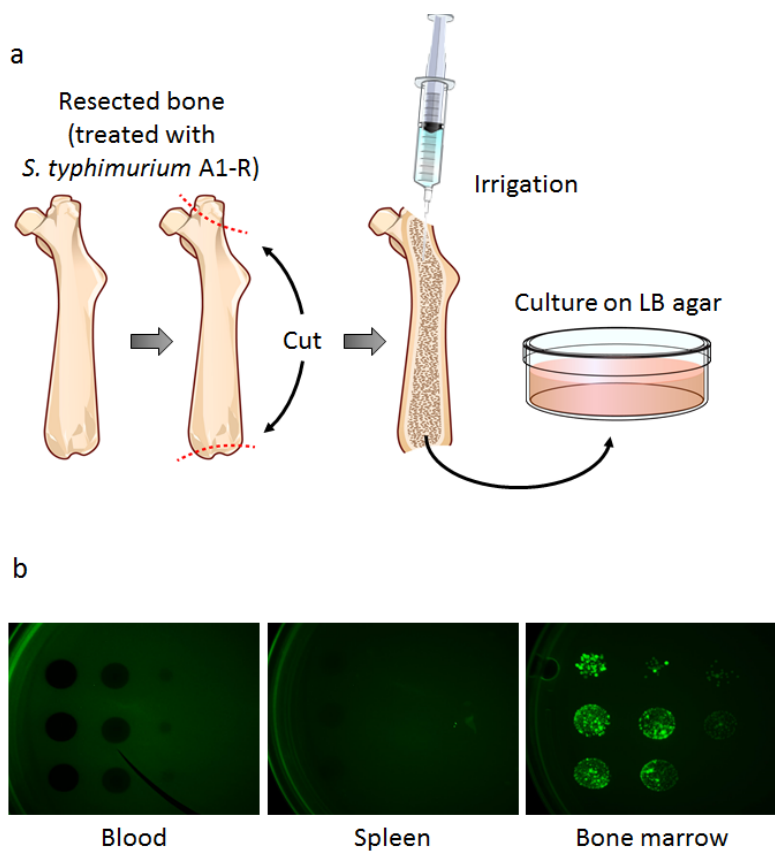

Figure 2: Distribution of $S$. typhimurium A1-R in bone marrow and other organs. One, 2, 3, 7, 14, and 28 days after injection of $S$. typhimurium A1-R, the non-tumor-bearing mice were sacrificed and blood, spleen, and bone marrow were harvested and irrigated with PBS. PBS containing $S$. typhimurium A1-R from each tissue was cultured on LB agar. a) Collection of bone marrow. After the resection of the femur, two holes were made in both ends. After irrigation, a portion of the PBS was cultured on LB agar for 24 hours. b) Colony formation of GFP-expressing $S$. typhimurium A1-R obtained from blood, spleen, and bone marrow which were harvested 14 days after $S$. typhimurium A1-R treatment. S. typhimurium A1-R fluorescent colonies were imaged with the OV100 Small Animal Imaging System. 


\section{S. typhimurium A1-R survives in bone marrow}

After injection of $S$. typhimurium A1-R $\left(5 \times 10^{7}\right.$ $\mathrm{CFU}$, i.v.) to non-tumor-bearing nude mice, blood, spleen, and bone marrow were cultured on Luria-Bertani (LB) agar (Fig. 2a). The presence of S. typhimurium A1-R was confirmed by GFP-expressing colony formation 24 hours after culture (Fig. 2b). These results showed that $S$. typhimurium A1-R survived for 2 weeks in bone marrow, compared to only 3 days in spleen. Blood had no colony formation on LB agar.

\section{In vivo selection of highly metastatic breast cancer cells}

MDA-MB-435-GFP cells formed experimental bone metastases after injection in the left cardiac ventricle injection of nude mice (Fig. 3a). Bone metastases become detectable by fluorescence six weeks after inoculation of parental MDA-MB-435-GFP cells $\left(2 \times 10^{5}\right)$, and

a

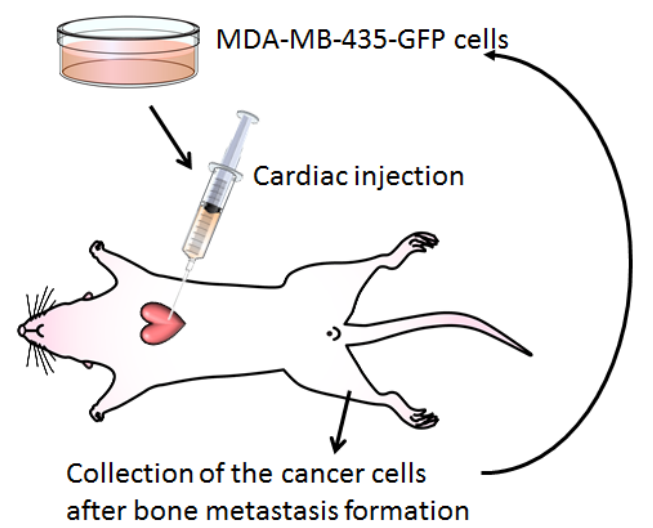

b

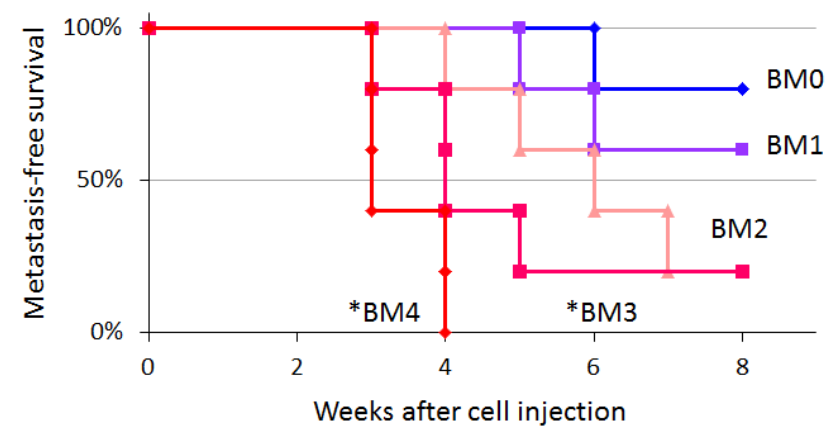

appeared in $20 \%$ of inoculated mice. High metastatic variants obtained after 1-4 cycles of in vivo selection were progressively termed MDA-MB-435-GFP-BM1, -BM2, -BM3, and -BM4. After 4 cycles of selection, the highly metastatic cell line MDA-MB-435-GFP-BM4 was obtained (Fig. 3b). MDA-MB-435-GFP-BM4 cells generate detectable bone metastases 3-4 weeks after inoculation, in $100 \%$ of the mice inoculated (Fig. 3c).

\section{Efficacy of $S$. typhimurium A1-R therapy on experimental bone metastasis}

Nude mice $(\mathrm{n}=10)$ were injected in the left ventricle with MDA-MB-435-GFP-BM4 cells $\left(2 \times 10^{5}\right)$. One week after cardiac injection, mice $(n=5)$ were treated 3 times with weekly i.v. injection of $S$. typhimurium A1-R (Fig. 4a). Four weeks after cardiac injection of MDA-MB-435-GFP-BM4 cells, fluorescence imaging showed experimental metastatic bone metastasis in all of the untreated control mice (Fig. 4b). In contrast, no $S$. typhimurium A1-R-treated mouse had bone metastasis during the 12-week observation period $(P=0.009)$ (Fig. $4 c)$.

\section{Efficacy of $S$. typmimurium A1-R on breast cancer cell growth in the tibia}

MDA-MB-435-GFP-BM4 cells $\left(5 \times 10^{5}\right)$ were injected into the intramedullary cavity of the tibia in nude mice $(\mathrm{n}=12)$ (Fig. 5a). Two weeks after intratibial injection of cancer cells, six mice were treated three times with weekly i.v. S. typhimurium A1-R (Fig. 5b).

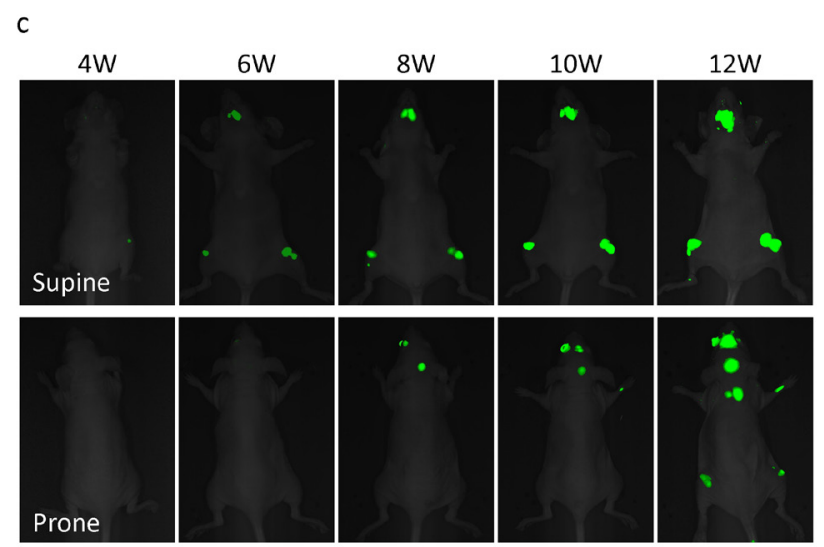

Figure 3: In vivo selection of highly brain-metastatic cancer cells. a) Schematic representation of the in vivo cyclic selection process for high bone-metastatic variants. MDA-MB-435-GFP cells were inoculated into the left cardiac ventricle of nude mice. Six weeks after injection, experimental bone metastases were detected by fluorescence imaging. Cancer cells were isolated from bone metastases and re-inoculated in the left ventricle after expansion in culture. Cells isolated from the second round of metastases were expanded in culture and re-inoculated in the left ventricle for a total of 4 cycles. b) Kaplan-Meier curves for metastasis-free survival of mice inoculated in the left ventricle with MDA-MB-435-GFP-BM1-4 cells compared with the parental MDA-MB-435-GFP cells $(\mathrm{BM} 0)(* \mathrm{p}<0.05)$. c) Timecourse imaging of breast cancer bone metastasis. MDA-MB-435-GFP-BM4 cells were inoculated into the left cardiac ventricle of nude mice. Fluorescence imaging visualized the progression of metastases in multiple bones including skull, femur, and vertebra. 
a

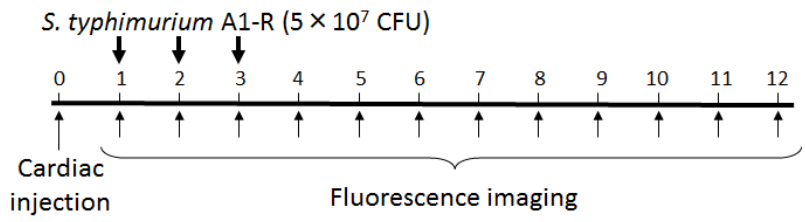

b
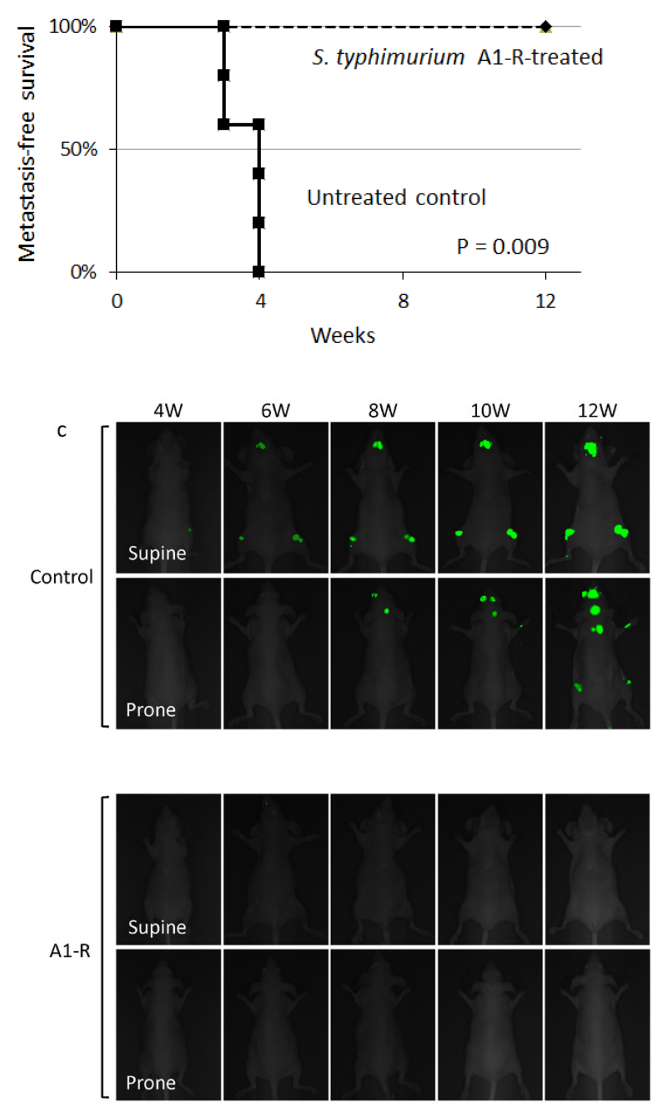

Figure 4: Efficacy of $S$. typhimurium A1-R on experimental bone metastasis after cardiac injection. a) Study protocol. MDA-MB-435-GFP-BM4 cells were injected into the left ventricle in nude mice $(\mathrm{n}=10)$. On day 7,14 , and $21, S$. typhimurium A1-R $\left(5 \times 10^{7} \mathrm{CFU} /\right.$ mouse, $\left.\mathrm{n}\right)$ were administered to mice $(\mathrm{n}=5)$. Fluorescence imaging was performed every week. b) Metastasis-free survival of mice treated with S. typhimurium A1-R or untreated controls was determined using the KaplanMeier method with log-rank test. c) Time-course fluorescence imaging of breast cancer bone metastasis with or without treatment of $S$. typhimurium A1-R. MDA-MB-435-GFP-BM4 cells were inoculated in the left cardiac ventricle of nude mice. Fluorescence imaging visualized the progression of metastases in multiple bones including skull, femur, and vertebrae in control mice. In contrast, there was no fluorescence in the mice treated with $S$. typhimurium A1-R.

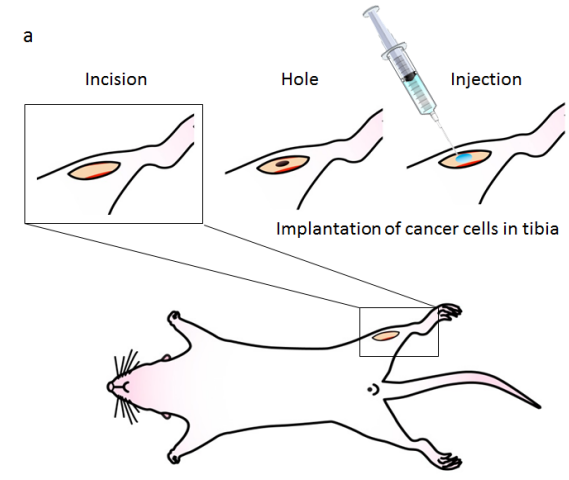

b
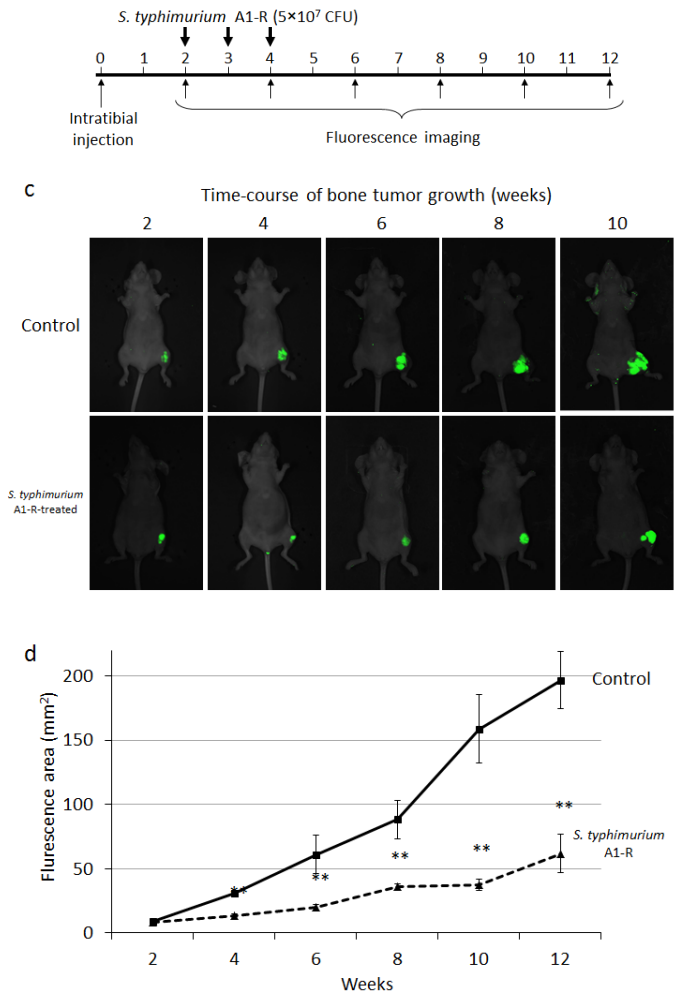

Figure 5: a) Experimental schema of approximately $5 \mathrm{~mm}$ midline skin incision was made to expose the tibial tuberosity. MDA-MB-435-BM4 cells $\left(2 \times 10^{5}\right)$ in $5 \mu 1$ Matrigel (BD Bioscience, San Jose, CA) were injected in the intramedullary cavity of the tibia. b) Study protocol. Two weeks after intratibial injection, fluorescence imaging was performed to confirm the growing GFP-expressing tumor using the iBOX Scientia Small Animal Imaging System (UVP LLC, Upland, CA, USA). Mice ( $\mathrm{n}=5)$ (treatment group) were administered S. typhimurium A1-R $\left(5 \times 10^{7} \mathrm{CFU}\right.$, i.v. $)$ once a week for 3 weeks. The remaining mice (untreated control group, $n=5$ ) were administered the same volume of PBS. Fluorescence imaging was performed on treated and untreated mice. GFP fluorescent areas were recorded every 2 weeks for 12 weeks using the iBOX. c) Time-course imaging of the GFP-expressing bone tumors in S. typhimurium A1-R therapy treated mice and untreated mice. d) Fluorescence area of bone tumors in untreated control and $S$. typhimurium treated mice. Data are expressed as the mean $\pm \mathrm{SE}$. Differences between groups were analyzed with the Student's $t$-test. ${ }^{*} p<0.01$ compared with the untreated control group. 
Fluorescence imaging demonstrated that the control mice had rapid tumor growth of the tibial tumor. In contrast, the S. typhimurium A1-R-treated mice had slow growth (Fig. 5c). The fluorescent tumors area of the untreated control mice and S. typhimurium A1-R-treated mice 10 weeks after bacterial therapy was $196.6 \pm 22.1 \mathrm{~mm}^{2}$ and $61.8 \pm 15.0 \mathrm{~mm}^{2}$, respectively $(P<0.001)$ (Fig. $\left.5 \mathrm{~d}\right)$. The bone marrow was observed with an FV1000 confocal microscope to confirm the presence of GFP-expressing cancer cells.

The present study demonstrates that $S$. typhimuium A1-R has and could significantly inhibit or prevent bone metastasis. These results indicate a promising approach to a currently highly treatment-resistant disease.

\section{MATERIALS AND METHODS}

\section{Cell culture}

MDA-MB-435-GFP cells and MDA-MB-435-RFP cells were generated as previously described [20-25]. Cells were maintained in Dulbecco's modified Eagle's medium high glucose supplemented with $10 \%$ FBS +200 $\mu \mathrm{g} / \mathrm{mL}$ G418 (Gibco). Cells were subcultured for at least 3 passages before harvesting at their linear growth phase (approximately $70-80 \%$ confluent) for cardiac injection of $2 \times 10^{5}$ cells.

\section{Preparation of S. typhimurium A1-R}

GFP-expressing Salmonella typhimurium A1-R bacteria (AntiCancer Inc., San Diego, CA, USA) were grown overnight on LB medium (Fisher Sci., Hanover Park, IL, USA) and then diluted 1:10 in LB medium. Bacteria were harvested at late-log phase, washed with PBS, and then diluted in PBS [4, 5].

\section{S. typhimurium A1-R killing of breast cancer cells in vitro}

MDA-MB-435-GFP or MDA-MB-435-RFP cells were planted in $35 \mathrm{~mm}$ dishes $\left(2 \times 10^{3}\right)$. S. typhimurium A1-R-GFP was grown in LB medium and added to the cancer cells $\left(1 \times 10^{8}\right.$ or $1 \times 10^{9} \mathrm{CFU} /$ dish $)$. After $1 \mathrm{~h}$ incubation at $37^{\circ} \mathrm{C}$, the cells were rinsed and cultured in medium containing gentamycin sulfate $(100 \mu \mathrm{g} / \mathrm{ml})$ to kill external but not internal bacteria. Invasion and destruction of MDA-MB-435-RFP cells by $S$. typhimurium A1-R-GFP was visualized with the FV1000 confocal microscope. Eight days after treatment with $S$. typhimurium A1-R, MDA-MB-435-GFP colonies were fixed in methanol and stained with $1 \%$ crystal violet as previously described [26]. ImageJ (National Institute of Mental Health, Bethesda,
Maryland, USA) was used to quantify the colonies of the cells.

\section{Distribution of $S$. typhimurium A1-R in blood, spleen, and bone marrow tissue}

Tumor-free nude mice were injected with $S$. typhimurium A1-R $\left(5 \times 10^{7} \mathrm{CFU}\right.$, i.v.). On days 1, 2, 3, 7, 14, and 28 after $S$. typhimurium A1-R GFP injection, femurs were taken from 3 mice and irrigated with PBS. Spleens were minced and mixed with PBS, as was blood. The PBS, including $S$. typhimurium A1-R from each tissue, was plated on LB agar containing $50 \mu \mathrm{g} / \mathrm{mL}$ ampicillin to identify $S$. typhimurium A1-R in each tissue. Fluorescent $S$. typhimurium A1-R colonies were observed with the OV100 Small Animal Imaging System (Olympus Corp., Tokyo, Japan).

\section{In vivo cycle selection of highly metastatic breast cancer cells}

MDA-MB-435-GFP cells were harvested from subconfluent cell culture plates, washed with PBS, and resuspended in PBS. Cells $\left(2 \times 10^{5}\right)$ were injected into the left cardiac ventricle of female nude mice using a $27 \mathrm{G}$ needle. Mice were anesthetized with a ketamine mixture $(10 \mu \mathrm{l}$ ketamine, HCL, 7,6 $\mu \mathrm{l}$ xylazine, $2.4 \mu \mathrm{l}$ acepromazine maleate and $10 \mu \mathrm{H}_{2} \mathrm{O}$ ) before injection. A successful injection was characterized by the pumping of arterial blood into the syringe. Development of bone metastases was initially monitored with an Illumatool imaging system (Lightools Research, Encinitas, CA, USA). To isolate cancer cells from the bone metastasis, mice were sacrificed, and the affected bones were excised. Both ends of the bones were cut open. A one $\mathrm{ml}$ syringe with a $27 \mathrm{G}$ needle was filled with PBS and inserted into one end of the bone. Mouse bone marrow cells as well as cancer cells were forced out from the other end by applying pressure to the syringe. Cells were collected by centrifugation and washed once with PBS before being cultured at $37^{\circ} \mathrm{C}$. After two weeks of culture, a pure population of human cancer cells was obtained as confirmed by fluorescence imaging. After 4 cycles of this procedure, we obtained a highly metastatic cells line, termed MDA-MB-435-GFP-BM4. Time-course imaging of the mice after cardiac injection of MDA-MB-435-GFPBM4 demonstrated progression of multiple metastases to bone including skull, femur, and vertebrae.

\section{Efficacy of S. typhimurium A1-R therapy on early-stage experimental bone metastasis}

MDA-MB-435-GFP-BM4 cells $\left(2 \times 10^{5}\right)$ were injected intracardially in nude mice. One week after 
injection, mice $(\mathrm{n}=5)$ (treatment group) were administered S. typhimurium A1-R $\left(5 \times 10^{7} \mathrm{CFU}\right.$, i.v. $)$ once a week for 3 weeks. The remaining mice (control group) were administered the same volume of PBS. To evaluate metastasis-free survival, GFP-expressing lesions were initially observed using the Illumatool every week. Metastatic bone lesions were also imaged every two weeks using the iBOX Scientia Imaging System (UVP LLC, Upland, CA, USA). Metastasis-free survival was defined as the time from cardiac injection of cancer cells to the time of detection of bone metastases with the Illumatool. At the end of the follow-up, the metastases were excised and the bone marrow was washed with PBS to confirm the presence of GFP-expressing cancer cells.

\section{Efficacy of $S$. typhimurium therapy on breast cancer cell growth in the tibia}

A midline skin incision $(5 \mathrm{~mm})$ was made just below the knee joint to expose the tibial tuberosity (Fig. 6). Matrigel ( $5 \mu \mathrm{L})$ (BD Bioscience, San Jose, CA) and MDA-MB-435-GFP-BM4 cells $\left(5 \times 10^{5}\right)$ were co-injected into the intramedullary cavity of the tibia with a $0.5 \mathrm{~mL}$ $28 \mathrm{G}$ latex-free insulin syringe $(0.5 \mathrm{~mL} 28 \mathrm{G})$ (TYCO Health Group LP, Mansfield, MA). The skin was closed with a 6-0 suture. Two weeks after injection, fluorescence imaging was performed to confirm the GFP-expressing tumor was growing, using the iBOX. Nude mice $(n=5)$ were administered $S$. typhimurium A1-R $\left(5 \times 10^{7} \mathrm{CFU}\right.$, i.v. $)$ once a week for 3 weeks. The remaining mice (untreated control group) were administered the same volume of PBS. Fluorescence imaging was performed on treated and untreated mice, and GFP-expressing areas were recorded every 2 weeks for 12 weeks using the iBOX.

\section{Statistical analysis}

Data showing comparisons between two groups were assessed using the Student's $t$-test. Comparisons among more than two groups were assessed using analysis of variance (ANOVA). The Kaplan-Meier method was used for bone metastasis-free survival and log-rank test was used for statistical significance of the difference between the two groups. Differences were considered significant when $\mathrm{p}<0.05$. Data are expressed as mean \pm SEM. Statistical analyses were performed with EZR (Saitama Medical Center, Jichi Medical University).

\section{DEDICATION}

This paper is dedicated to the memory of A. R. Moossa, MD.

\section{ACKNOWLEDGEMENTS}

This work was supported by the National Cancer Institute grant CA132971.

\section{CONFLICTS OF INTEREST}

YZ and MZ are employees of AntiCancer Inc. SM, SY, YM, FU, MY, YH, HK, KH, NY and RMH are or were unsalaried associates of AntiCancer Inc. There are no other competing financial interests.

\section{REFERENCES}

1. Hamaoka T, Madewell JE, Podoloff DA, Hortobagyi GN, Ueno NT. Bone imaging in metastatic breast cancer. J Clin Oncol 2004; 22:2942-2953.

2. Pawelek JM, Low KB, Bermudes D. Bacteria as tumourtargeting vectors. Lancet Oncol 2003; 4:548-556.

3. Toso JF, Gill VJ, Hwu P, Marincola FM, Restifo NP, Schwartzentruber DJ, Sherry RM, Topalian SL, Yang JC, Stock F, Freezer LJ, Morton KE, Seipp C, et al. Phase I study of the intravenous administration of attenuated Salmonella typhimurium to patients with metastatic melanoma. J Clin Oncol 2002; 20:142-152.

4. Zhao M, Yang M, Li XM, Jiang P, Baranov E, Li S, Xu M, Penman S, Hoffman RM. Tumor-targeting bacterial therapy with amino acid auxotrophs of GFP-expressing Salmonella typhimurium. Proc Natl Acad Sci USA 2005; 102:755-760.

5. Zhao M, Yang M, Ma H, Li X, Tan X, Li S, Yang Z, Hoffman RM. Targeted therapy with a Salmonella typhimurium leucine-arginine auxotroph cures orthotopic human breast tumors in nude mice. Cancer Res 2006; 66:7647-7652.

6. Zhao M, Geller J, Ma H, Yang M, Penman S, Hoffman RM. Monotherapy with a tumor-targeting mutant of Salmonella typhimurium cures orthotopic metastatic mouse models of human prostate cancer. Proc Natl Acad Sci USA 2007; 104:10170-10174.

7. Nagakura C, Hayashi K, Zhao M, Yamauchi K, Yamamoto N, Tsuchiya H, Tomita K, Bouvet M, Hoffman RM. Efficacy of a genetically-modified Salmonella typhimurium in an orthotopic human pancreatic cancer in nude mice. Anticancer Res 2009; 29: 1873-1878.

8. Hayashi K, Zhao M, Yamauchi K, Yamamoto N, Tsuchiya H, Tomita K, Hoffman RM. Cancer metastasis directly eradicated by targeted therapy with a modified Salmonella typhimurium. J Cell Biochem 2009; 106:992-998.

9. Yam C, Zhao M, Hayashi K, Ma H, Kishimoto H, McElroy M, Bouvet M, Hoffman RM. Monotherapy with a tumortargeting mutant of S. typhimurium inhibits liver metastasis in a mouse model of pancreatic cancer. J Surg Res 2010; 164:248-255.

10. Kimura H, Zhang L, Zhao M, Hayashi K, Tsuchiya H, 
Tomita K, Bouvet M, Wessels J, Hoffman RM. Targeted therapy of spinal cord glioma with a genetically-modified Salmonella typhimurium. Cell Proliferation 2010; 43:41-48.

11. Liu F, Zhang L, Hoffman RM, Zhao M, Vessel destruction by tumor-targeting Salmonella typhimurium A1-R is enhanced by high tumor vascularity. Cell Cycle 2010; 9:4518-4524.

12. Leschner S, Westphal K, Dietrich N, Viegas N, Jablonska J, Lyszkiewicz M. Tumor invasion of Salmonella enterica serovar Typhimurium is accompanied by strong hemorrhage promoted by TNF $\alpha$. PLoS ONE 2009; 4:e6692.

13. Tome Y, Zhang Y, Momiyama M, Maehara H, Kanaya F, Tomita K, Tsuchiya H, Bouvet M, Hoffman RM, Zhao M. Primer dosing of S. typhimurium A1-R potentiates tumor-targeting and efficacy in immunocompetent mice. Anticancer Res 2013; 33:97-102.

14. Zhang $\mathrm{Y}$, Zhang N, Su S, Hoffman RM, Zhao M. Salmonella typhimurium A1-R tumor targeting in immunocompetent mice is enhanced by a Traditional Chinese Medicine herbal mixture. Anticancer Res 2013; 33: 1837-1843.

15. Uchugonova A, Zhao M, Zhang Y, Weinigel M, König K, Hoffman RM. Cancer-cell killing by engineered Salmonella imaged by multiphoton tomography in live mice. Anticancer Res 2012; 32:4331-4338.

16. Hiroshima Y, Zhao M, Zhang Y, Maawy A, Hassanein MK, Uehara F, Miwa S, Yano S, Momiyama M, Suetsugu A, Chishima T, Tanaka K, Bouvet M, et al. Comparison of efficacy of Salmonella typhimurium A1-R and chemotherapy on stem-like and non-stem human pancreatic cancer cells. Cell Cycle 2013; 12:2774-2780.

17. Hiroshma Y, Maawy A, Sato S, Murakami T, Uehara F, Miwa S, Yano S, Momiyama M, Chishima T, Tanaka K, Bouvet M, Endo I, Hoffman RM. Hand-held highresolution fluorescence imaging system for fluorescenceguided surgery of patient and cell-line pancreatic tumors growing orthotopically in nude mice. J Surg Res 2014; 187:510-517.

18. Hiroshima Y, Maawy A, Metildi CA., Zhang Y, Uehara F, Miwa S, Yano S, Sato S, Murakami T, Momiyama M, Chishima T, Tanaka K, Bouvet M, et al. Successful fluorescence-guided surgery on human colon cancer patient-derived orthotopic xenograft mouse models using a fluorophore-conjugated anti-CEA antibody and a portable imaging system. J Laparoendosc Adv Surg Tech A 2014; 24:241-247.

19. Hiroshima Y, Zhao M, Maawy A, Zhang Y, Katz MH, Fleming JB, Uehara F, Miwa S, Yano S, Momiyama M, Suetsugu A, Chishima T, Tanaka K, et al. Efficacy of Salmonella typhimurium A1-R versus chemotherapy on a pancreatic cancer patient-derived orthotopic xenograft (PDOX). J Cell Biochem 2014; 115:1254-1261.

20. Li X, Wang J, An Z, Yang M, Baranov E, Jiang P, Sun F, Moossa AR, Hoffman RM. Optically imageable metastatic model of human breast cancer. Clin Exp Metastasis 2002;
19:347-50.

21. Yang M, Reynoso J, Jiang P, Li L, Moossa AR, Hoffman RM. Transgenic nude mouse with ubiquitous green fluorescent protein expression as a host for human tumors. Cancer Res 2004; 64:8651-8656.

22. Hoffman RM, Yang M. Subcellular imaging in the live mouse. Nature Protoc 2006; 1:775-782.

23. Hoffman RM, Yang M. Color-coded fluorescence imaging of tumor-host interactions. Nature Protoc 2006; 1:928-935.

24. Hoffman RM, Yang M. Whole-body imaging with fluorescent proteins. Nature Protoc 2006; 1:1429-1438.

25. Zhang Q, Fan H, Shen J, Hoffman RM, Xing HR. Human breast cancer cell lines co-express neuronal, epithelial, and melanocytic differentiation markers in vitro and in vivo. PLoS One 2010; 5:e9712.

26. Miwa S, Yano S, Tome Y, Sugimoto N, Hiroshima Y, Uehara F, Mii S, Kimura H, Hayashi K, Efimova EV, Fujiwara T, Tsuchiya H, Hoffman RM. Dynamic colorcoded fluorescence imaging of the cell-cycle phase, mitosis, and apoptosis demonstrates how caffeine modulates cisplatinum efficacy. J Cell Biochem 2013; 114:2454-2460. 